\title{
Asociación entre la duración de la lactancia materna y el riesgo de muerte súbita del lactante
}

\author{
Association between the duration of breastfeeding and the risk of sudden infant death
}

Thompson J y col. Pediatrics. 2017;140(5):e20171324

\section{Objetivos}

Evaluar la asociación entre la duración y la exclusividad de la lactancia materna y el síndrome de muerte súbita del lactante.

\section{Diseño}

Metaanálisis de datos individuales de ocho estudios de casos y controles.

\section{Lugar}

Nueva Zelanda, Inglaterra, Irlanda, Suecia, Noruega, Dinamarca, Holanda, Austria, Hungría, Ucrania, España, Italia, Rusia, Eslovenia, Francia, Bélgica, Polonia, Alemania, Escocia, EE.UU.

\section{Pacientes}

Fueron incluidos un total 9104 pacientes de entre 0 y 52 meses, de los cuales 2267 fueron casos de muerte súbita del lactante y 6837 controles.

\section{Medición de resultados principales}

Tomando como referencia a los niños que no recibieron lactancia materna, fueron calculados los Odds Ratios resultantes del análisis multivariable de muerte súbita para diferentes estratos de duración creciente de la lactancia materna (exclusiva y parcial). Los 19 potenciales factores de confusión por los que se realizó el ajuste fueron: posición al dormir durante el último sueño del lactante, tabaquismo materno durante el embarazo, que el lactante hubiera dormido la última vez con otra persona en la misma cama, que el lactante hubiera dormido la última vez en una habitación compartida con un adulto pero sin compartir la cama, uso de chupete la última vez que el lactante durmió, edad materna, controles prenatales, estado civil, paridad, nivel educativo materno, nivel socioeconómico, edad del lactante, sexo del lactante, admisión a alguna unidad de cuidados especiales para niños, estación del año en que el lactante falleció, peso al nacer, edad gestacional, embarazo múltiple y nacimiento por cesárea.

\section{Resultados principales}

La tabla 1 describe la asociación documentada entre la duración y la exclusividad de la lactancia materna y el síndrome de muerte súbita del lactante.

Tabla 1: Asociación entre la duración y la exclusividad de la lactancia materna y el síndrome de muerte súbita del lactante.

\begin{tabular}{|c|c|c|}
\hline \multirow[b]{2}{*}{$\begin{array}{l}\text { Duración de la lactancia materna } \\
\text { (meses) }\end{array}$} & \multicolumn{2}{|c|}{ Tipo de lactancia } \\
\hline & $\begin{array}{c}\text { No Exclusiva } \\
\text { OR ajustado (IC 95\%) }\end{array}$ & $\begin{array}{c}\text { Exclusiva } \\
\text { OR ajustado (IC 95\%) }\end{array}$ \\
\hline $\begin{array}{l}\text { Nunca } \\
0 \text { a } 2\end{array}$ & $\begin{array}{c}1.00 \\
0,91(0,68 \text { a } 1,21)\end{array}$ & $\begin{array}{c}1,00 \\
0,82(0,59 \text { a } 1,14)\end{array}$ \\
\hline $\begin{array}{c}2 \text { a } 4 \\
4 \text { a } 6 \\
\text { Más de } 6\end{array}$ & $\begin{array}{l}0,60(0,44 \text { a } 0,82) \\
0.40(0,26 \text { a } 0,63) \\
0,36(0,22 \text { a } 0,61)\end{array}$ & $\begin{array}{c}0.61(0,42 \text { a } 0,7) \\
0,46(0,29 \text { a } 0,74) \\
\text { NA }\end{array}$ \\
\hline
\end{tabular}

IC: intervalo de confianza

\section{Conclusiones}

La lactancia materna mantenida por al menos dos meses se asoció con una disminución del riesgo de muerte súbita de aproximada- mente un $40 \%$, sin que sea necesario que sea exclusiva para conferir este potencial efecto protector.

Fuentes de financiamiento: no informada

\section{Comentario}

Este estudio provee más argumentos para recomendar que la lactancia materna dure al menos dos meses para conceder un efecto protector contra el síndrome de muerte súbita del lactante. Alcanzando esta duración, el riesgo disminuye aproximadamente el $40 \%$ y se torna cada vez menor, conforme se prolonga la duración de la lactancia materna, lo que podría ser interpretado como un efecto dosis-respuesta. Por otro lado, estos resultados revelan que la lactancia materna exclusiva no sería superior a la lactancia parcial respecto de este potencial efecto protector. Entre las limitaciones de estos resultados, y si bien es probable que nunca sea posible contar con otro tipo de evidencia como la proveniente de estudios experimentales, recordamos que en los estudios observacionales no es posible ajustar por todos los potenciales sesgos de confusión. En ese contexto, resulta interesante que el efecto "protector" de la lactancia materna se atenúa luego de ajustar por el nivel socioeconómico, lo que podría hacer pensar que el nivel socioeconómico influye tanto sobre la probabilidad de que un lactante reciba lactancia materna como la de que sufra una muerte súbita. Por otro lado, no podemos olvidar que la mayoría los estudios incluidos en este meta-análisis fueron realizados en países desarrollados y que no se contó con información proveniente de Latinoamérica. Esto plantea la duda de si los resultados pueden extrapolarse a nuestra población. Relacionado con esto, se encuentra el hecho de que el efecto del nivel socioeconómico podría no darse de la misma manera en países periféricos y/o con mayor inequidad en la distribución del ingreso.

\section{Conclusiones de la comentadora}

Si bien la muerte súbita del lactante no constituye un problema de salud pública, es un acontecimiento trágico en las familias. El nuevo conocimiento que arroja este estudio nos permite refinar nuestra consejería y darles reaseguro a aquellas madres que no puedan mantener una lactancia materna exclusiva durante seis meses como es lo recomendado habitualmente.

Leticia Gavoto [ Servicio de Medicina Familiar y Comunitaria, Hospital Italiano de Buenos Aires leticia.gavoto@ hospitalitaliano.org.ar ] 